\title{
Evaluation of total risk exposure and insurance premiums in the maritime industry
}

\author{
Sabine Knapp ${ }^{1}$ and Christiaan Heij ${ }^{2}$ \\ Econometric Institute, Erasmus University Rotterdam \\ Econometric Institute Report EI 2016-25
}

\begin{abstract}
This study provides an empirical evaluation of maritime risk exposure expressed as the monetary value at risk (MVR), which incorporates life of crew and passengers, vessel value of hull and machinery, carried cargo value, third party liabilities, and potential external damages like pollution. MVR is based on individual safety quality data of about 130,000 vessels, on insurable values related to various potential damages, and on proxies for fractions of values lost at incidents. MVR provides a tool to enhance strategic planning of maritime administrations and insurance providers, which is illustrated by a high level comparison of annual risk exposure with insurance premiums for 2010 to 2014 . The analysis reveals a global annual insurable value of 30.6 trillion USD with associated annual MVR of 38.8 billion USD for very serious and serious incidents. Although oil tankers show the highest risk exposure (1.75 million USD per tanker per year), safety qualities are found to be best for this ship type (1.4\% annual incident risk) and worst for container vessels $(2.8 \%)$. Annual growth rates in total risk exposure are mostly positive with highest value for dry bulk carriers $(27.8 \%)$, whereas risk exposure tends to decline for pollution of oil tankers $(-2.0 \%)$ and passenger vessels $(-11.3 \%)$, and for loss of life of oil tankers $(-1.9 \%)$ and dry bulk carriers $(-1.4 \%)$ but not of passenger vessels $(6.9 \%)$. A comparison across administrative dimensions reveals that most risk exposure lies with old open registries and with beneficial owners and DoC companies located in high income countries. Comparison with global insurance premiums suggests reasonably adequate coverage of maritime risks (excluding cargo). Our analysis indicates under-insurance of risk by around 5\%, corresponding to about 1 billion USD per year, with some uncertainties remaining for the actual loss fractions of the various involved damages.
\end{abstract}

\section{Keywords}

shipping incident; monetary value at risk; risk exposure; insurance; pollution; loss of life

\footnotetext{
${ }^{1}$ Econometric Institute, Erasmus School of Economics, Erasmus University Rotterdam, P.O. Box 1738, 3000 DR Rotterdam, The Netherlands; e-mail knapp@ese.eur.nl

2 Econometric Institute, Erasmus School of Economics, Erasmus University Rotterdam, P.O. Box 1738, 3000 DR Rotterdam, The Netherlands; corresponding author, phone +31-10-4081264, fax +31-10-4089162, e-mail heij@ese.eur.nl
} 


\section{Introduction}

The continual growth of international trade over the last decades caused increasing maritime activities with associated magnifications of risk. Shipping is exposed to ship economic cycles (Stopford, 2009), and economic pressure to minimize costs in downward cycles can affect safety at sea (Bijwaard and Knapp, 2009), implying upward trends in risk exposure in the maritime industry. The purpose of this study is to provide an empirical evaluation of total risk exposure expressed as the monetary value at risk (MVR). This concept was employed in Heij and Knapp (2012), but has been refined and extended here to allow for comparison with insurance figures from marine underwriters and P\&I Clubs. The main components of MVR consist of the individual safety qualities of vessels, the total insurable value of vessels, and proxies for fractions of various types of values that can get lost due to damages from shipping incidents.

The total insurable value (TIV) of a vessel is defined in terms of the total insurable values of hull and machinery, cargo values, and insurance limits based on international conventions for marine liabilities including loss of life and pollution costs but excluding damages to marine ecosystems. The vessel-specific monetary value at risk is defined as the weighted average of potential damages of these values, with weights based on the conditional probability for each damage type (Knapp et al, 2011; Heij and Knapp, 2012) and on expected loss fractions per damage type. The associated incident and damage type probabilities for each vessel are estimated from empirical data based on a unique dataset covering the world fleet.

In our risk assessment, we distinguish between two levels of seriousness of shipping incidents, according to IMO definitions (IMO, 2000). The first level is that of very serious (including total loss) and serious (TLVSS) incidents. This incident class has been identified as most relevant for the analysis of risk exposure in a wider context (Vander Hoorn and Knapp, 2015). Its applications include operational and strategic planning to mitigate risk exposure by means of risk control options, such as alerting for high risk vessels or situations, improved targeting of vessels for inspections, and developing risk prediction scenarios for planning and allocation of assets across large areas. The MVR based on TLVSS incidents can be interpreted as the potential damage value (expressed in USD) for given vessel risk profile and insurable values, which can be combined with other risk layers such as metocean conditions and vessel traffic densities.

The second risk assessment level includes all types of shipping incidents, which provides the appropriate basis to compare MVR with insurance premiums from the International Union of Marine Insurance (IUMI) and the Prevention and Indemnity (P\&I) Clubs. The main insurance categories reported by IUMI publicly each year are hull and machinery, transport cargo, and marine liability. Marine liability is primarily covered by the P\&I Clubs and includes loss of life, pollution, and other third party liabilities. In order to compare premiums with risk exposure, the monetary values at risk are down-weighted by means of loss fractions specified per class of seriousness and per insurable value type. This kind of information is not readily available in the industry, so that scenarios for loss fractions will be based on empirical sources where possible and augmented by expert insights where needed. 
It is worth noting that several factors complicate a direct comparison of premiums with actual risk exposure. Insurance is a global enterprise and involves many parties. It is believed that IUMI and the P\&I clubs insure approximately 95 percent of all risk (Siddiqui and Verma, 2015), but public insurance figures provide only a partial view of total risk exposure. A portion of total risk exposure is not insured due to vessel retentions or deductibles that are not reported and that can vary depending on the insurance type and owner. Furthermore, damages to the marine ecosystem vary considerably (Kontovas et al, 2010) and some cannot be valued in monetary terms (Grey, 1999). For the pollution incident of the tanker 'Prestige' in 2002, for example, it has been estimated that only two percent of the long-term costs including environmental damages of 8.5 billion euro were paid out, so that the society at large had to pay 98 percent of the burden (Liu and Wirtz, 2006). Another more recent example is the pollution incident of 'Sheng Neng 1' in 2010 in the Great Barrier Reef, for which the Australian Commonwealth sought for compensation of 120 million AUD in damages of which only 39.9 AUD million could be recovered.

\section{Data}

The employed data consist of a unique combination of multiple sources and covers the years 2010 till 2014. The information used to estimate ship-specific incident and damage type probabilities combines world fleet ship-particular data, incident data, and inspection data. The database contains 501,095 observations of 130,307 individual vessels covering all relevant ship types. Inspection data consist of global port state control inspection outcomes, including deficiency information and detentions. Global information on 18,602 maritime incidents (24,567 including near misses, and 9,549 TLVSS incidents) was combined from four different sources (IMO, IHS Markit, LLIS, and AMSA) to achieve best possible coverage of incidents and to reduce reporting biases for very serious and serious incidents (Hassel et al, 2011). The observations were manually reclassified for seriousness according to IMO definitions for very serious (including total loss), serious, and less serious (IMO, 2000). The AMSA incident data contain some 'near misses' which are used as lagged explanatory factors in the employed risk models. Duplicates across the four data sources were eliminated and first events were identified when possible in order to facilitate the reclassification of incident types into the five considered damage types (Wood, 1995; Knapp et al, 2011): hull and machinery, cargo, pollution, loss of life, and other third party liabilities. Missing ship particulars of incident data were complemented when possible to improve data quality.

The total insurable value (TIV) provides an estimate at the individual ship level of the sum total of the insurable values of each of the five damage types. Table 1 lists the sources used to derive the TIV for each damage category and compares these categories with the four IUMI premium categories. The table also shows the percentage coverage of world tonnage for the relevant conventions for loss of life, oil pollution, and other third party liabilities. In the case of the Athens convention, its application is not restricted to signatories as flag state but also includes trading areas. These data provide an update of the TIV values of Knapp et al (2011) and Heij and Knapp (2012) by including legislation up to December 2014. The value of hull and machinery is based on second-hand prices from the Shipping Intelligence Network 
(SIN) of Clarkson's. Average cargo values by DWT per day are estimated by combining trade statistics from UNCTAD with data from Global Insight. The insured values for loss of life, oil pollution, and other third party liabilities are based on international conventions as listed in Table 1, and special drawing rights (SDR's) have been converted into USD to obtain a common currency for all TIV components. Liability limits for loss of life and injuries for passenger ships follow the requirements of the Athens Convention of 1974 and the 2002 Protocol for 400,000 SDR per passenger and event. This is complemented by the International Convention on Limitation of Liability for Maritime Claims (LLMC) and its 1996 Protocol with a limit of 175,000 SDR times the total number of passengers for each event.

Pollution is of special interest because of its costly consequences. Whereas vessel damage causes on average six percent damage to other property, oil cargo spillage has been estimated to cause 155 percent external damage (Talley, 1999). Oil pollution limits cover oil as cargo and oil as bunker. Oil pollution limits for cargo of tankers are covered by the International Convention on Civil Liability for Oil Pollution Damage (CLC92) and depend on vessel size with a maximum of 59.7 million SDR. This has been supplemented by the cover from the International Convention on the Establishment of an International Fund for Oil Pollution Damage Compensation (IOPC Fund) and the Supplementary Fund of 2003 with maxima of respectively 203 million SDR and 750 million SDR, independent of vessel size. Oil pollution limits from bunkers apply to all ships and are provided by LLMC, along with other third party damage limits that depend on vessel size. The SDR start at a million for ships not exceeding 2,000 gross tonnage, with additional SDR allocations for three further size categories.

Annual aggregated premium data for 2010-2014 were obtained from IUMI and Seltmann (2015) for four insurance categories: hull and machinery, cargo and transport, marine liabilities, and offshore and energy activities. The latter category falls outside the scope of our analysis. Marine liabilities were supplemented by figures from the International P\&I Clubs (Seltmann, 2015) and by the Non International P\&I Clubs (Willis, 2016). No global information is available on premiums per vessel or on the number and types of insured vessels. A rough comparison is available for vessels over 1,000 gross tonnage, as the industry has reported that 53,845 vessels of this size will be insured for 2016 (Cefor, 2015).Our database has 49,685 vessels of this size for 2014, and over 2011-2014 this number has grown by about 1,000 vessels per year so that about 51,000-52,000 vessels would be expected for 2016. These figures suggest a fairly close match between the two vessel databases.

$<<$ Insert Table 1 around here. $>>$

\section{Methodology}

The risk evaluation methodology is based on the monetary value at risk (MVR) in Heij and Knapp (2012), which is updated and extended to allow comparison with insurance premiums. MVR is defined as the weighted average of potential damages with weights equal to the probability of each damage type. The four major components in MVR are the following: 
- The ship-specific annual probability of an incident, both for TLVSS incidents and for all types of incidents (excluding near misses), to proxy the safety quality of the vessel.

- The ship-specific conditional probabilities for each damage type given that an incident has occurred; these conditional probabilities are based on TLVSS incidents only or on all incidents and concern five damage categories: hull and machinery, cargo, pollution, loss of life, and other third parties.

- The ship-specific total insurable value for each damage category, based on the limits provided by the legislative framework or industry values for cargo and vessel values.

- Loss fractions per incident type and damage type, based on IMO definitions for the level of seriousness of an incident (very serious including total loss, serious, less serious) in conjunction with empirical figures for loss of life and pollution.

The MVR concept of Heij and Knapp (2012) includes the first three components but excludes loss fractions, which will be required here for our study of premiums.

For each vessel and each year, the database contains incident (and damage type) indicators with value 1 if that vessel experienced in that year at least one incident (with that damage type) and with value 0 otherwise. The probability of incidents and damage types is related to vessel-specific information by means of the logit model, which defines this probability by the fraction $\exp (r) /(1+\exp (r))$ where $r=x_{1} b_{1}+\ldots+x_{\mathrm{k}} b_{\mathrm{k}}$ is a weighted average of the $k$ risk factors $\left(x_{1}, \ldots, x_{\mathrm{k}}\right)$. The choice of these risk factors and the numerical value of their weights is determined by sequential down-testing of logit models, starting with all possibly relevant risk factors available in the database and stopping when all remaining factors are significant at the five percent level. The estimation and testing procedures are based on quasi maximum likelihood (Greene, 2008) to obtain standard errors that are robust against possible misspecification of the assumed logistic distribution.

The initial selection of variables for both model types, that is, incidents and damage types, is based on Knapp (2006, 2013) and Knapp et al (2011). Due to the large amount of item classes, especially for flags, classifications, safety management (Document of Compliance, DoC) companies, and beneficial owners, some classes were regrouped. As compared to previous studies, several new variables were added, that is, the engine designer and engine builder as well as proxies for maritime expertise of owners, DoC companies, and countries of location. Another country grouping is based on the World Bank classification for income and development, with five groups according to high income, upper middle income, lower middle income, low income, and unknown income. The final model obtained after down-testing contains the following vessel-specific factors, both for the class of TLVSS incidents and for all types of incidents combined: ship type dummies, vessel age, vessel size, individual flag, classification society group, DoC company and beneficial owner country of location classified according to World Bank income groups, ship yard country interacted with vessel age groups, main engine designer (individual company), main engine builder (country of location), and information for the previous year on casualties and deficiencies detected at inspections. As the database contains a single observation per vessel per year, the estimated incident probabilities represent vessel-specific annual incident probabilities reflecting the safety quality per vessel. 
Due to the smaller sample sizes that are available for estimating conditional damage type probabilities, categorical variables like flag, class, company, owner, and engine designer and builder have to be aggregated to a higher level. The obtained conditional damage probability models differ per damage type but share some common risk factors that include vessel type, age, and size, as well as past safety information in terms of previous incidents and deficiencies and group indicators for ship yard, class, company, owner, and machine designer and builder. The resulting conditional damage type probabilities provide ship-specific spreads across the five considered damage types in case of an incident.

The monetary value at risk is estimated by combining the two probabilities described above with the total insurable values (TIV). Let the five damage categories be denoted by $j(j$ $=1, \ldots, 5)$ and let $V_{j}$ be the total insurable value for value type $j$. Then TIV is defined as the sum total of the five categories, so that TIV $=\sum_{j=1}^{5} V_{j}$. Further let $P_{i n c}$ be the probability of an incident during a period of one calendar year and let $P_{j}$ be the conditional probability of damage category $j$ occurring in case of an incident. Then the monetary value at risk (MVR) of a vessel is defined by (Heij and Knapp, 2012):

$$
\operatorname{MVR}=P_{i n c} \times\left(\sum_{j=1}^{5} P_{j} \times V_{j}\right) .
$$

We will consider two versions of MVR, that is, MVR-S where both $P_{i n c}$ and $P_{j}(j=1, \ldots, 5)$ are estimated using the class of TLVSS incidents, and MVR-A based on all types of incidents (TLVSS and less serious incidents, but excluding near misses). MVR is similar in spirit to the factor-weighted risk index proposed by $\mathrm{Li}$ et al (2009) and the traditional risk measure in Siddiqui and Verma $(2013,2015)$. We will focus mostly on MVR-S, as TLVSS incidents constitute the major source of maritime risk exposure, and we use MVR-A only in the comparison with premiums because the premium data originate from all incidents, including less serious ones.

Here it should be noted that MVR-A in a sense measures the maximal value at risk, as it incorporates the full value of $V_{j}$ in case damage of type $j$ occurs. For many incidents, only a limited part of the full value will be lost, depending on the severity of the incident. This applies not only for damage to hull and machinery, cargo losses and third party liabilities, but also for the very costly categories of loss of life and pollution. If life is lost at an incident with a passenger ship, then in most cases the far majority of lives are saved with injuries and liabilities below the limits that apply for loss of life. And if an oil tanker incident causes oil spills, then all or the majority of carried oil may be spilled for total loss and very serious incidents, but only a limited amount for serious incidents and none for less serious ones. The actual expected loss in case a fraction $F_{j}$ (with $0 \leq F_{j} \leq 1$ ) of value $V_{j}$ is lost is

$$
\mathrm{MVR}^{*}=P_{i n c} \times\left(\sum_{j=1}^{5} P_{j} \times V_{j} \times F_{j}\right)
$$

The loss fractions $F_{j}$ will depend on the severity of the incident and will be particularly important for loss of life of passenger ships and for pollution and associated marine liabilities of oil tankers. For the comparison with premiums, we will employ MVR-A* as measure of risk exposure, that is, MVR based on all classes of incidents (excluding near misses) and adjusted by loss fractions. 
As data on loss fractions are not readily available, we searched the literature to calibrate benchmark values. It has been reported that pollution claims constituted 4.4 percent of all maritime insurance claims in 1997 ( $\mathrm{Li}$ and Cullinane, 2003). Since we found no further information on loss fractions, we attempted to estimate them by combining incident data from our database with information from the International Tankers Owners Pollution Federation (ITOPF) and the Central Union of Marine Underwriters (CEFOR). We focused our attempts on the three largest (unadjusted) components of MVR, that is, loss of life of passenger ships, pollution of oil tankers, and hull and machinery of all ship types. The loss fractions are only used for the comparison of MVR with insurance premiums and we used the IMO definitions (IMO, 2000) as guidance for our final estimates of loss fractions.

The loss fraction for loss of life for the class of very serious incidents of passenger ships is defined as the fraction of the total number of lost lives and injuries over the total number of passenger and crew capacity (based on information from IMO and IHS Markit) carried by these ships at these incidents. The resulting loss fraction for loss of life at very serious incidents is 0.04. In a similar way, for the class of very serious incidents of oil tankers involving oil spills, the loss fraction for pollution is defined as the fraction of the total volume of oil spilled over the total estimated volume of oil carried by these tankers at these incidents. The resulting fraction is about 0.01 when based on the available data from ITOPF, but the incident data are incomplete and do not cover smaller pollution incidents. For this reason, we use the IMO definitions (IMO, 2000) as guidance and use pollution loss fractions of 0.05 for very serious and 0.01 for serious incidents.

For hull and machinery damages, we consulted figures from CEFOR on the fraction of average claims over average sum insured for hull, where claims above 5 million USD were available. The resulting average loss fraction irrespective of the seriousness of the incident is 0.42. Based on the IMO definitions (IMO, 2000), we increase the loss fraction for hull and machinery to 0.95 for very serious incidents, 0.60 for serious incidents, and 0.05 for less serious incidents. The data sources available to us did not allow for accurate assessment of the other loss fractions. Therefore, in our scenario, we specified loss fractions for cargo and for third party liabilities that are equal to those of hull and machinery, that is, 0.95 for very serious incidents, 0.60 for serious incidents, and 0.05 for less serious incidents.

\section{Results}

Our discussion of results is organized as follows. First we provide an overview of the levels and growth rates of MVR per ship type. Next we visualize the spread of MVR across flags, classification societies, safety management companies, and beneficial owners. And finally we compare the aggregate MVR of all incidents corrected for loss fractions (MVR-A*) with insurance premiums. We present results for the world fleet as well as for six major ship types: general cargo, dry bulk, container, oil tanker, passenger, and 'other' (excluding non-oil tankers, fishing fleet, and tugs). 


\section{Annual MVR}

Table A in the appendix provides descriptive statistics on MVR components, that is, incident probabilities, total insurable values, and database counts of vessels, incidents, and damage types. The average annual total insured value of the world fleet of about 100,000 vessels lies at 30.6 trillion USD, reducing to 30.4 trillion USD for about 71,000 vessels after excluding the fishing fleet and tugs. Oil tankers account for $49 \%$ of this value. The highest TIV apply for pollution of oil tankers (1.2 billion USD per tanker per year) and for loss of life of passenger ships ( 0.5 billion USD per ship per year). This is unsurprising, as these high values are due to the legislative frameworks mentioned earlier to cover liabilities involving oil pollution and loss of life. Oil tankers are relatively safe, with annual incident probabilities of $1.4 \%$ for TLVSS and $2.3 \%$ for any type of incident, whereas for other ship types these probabilities range respectively from $1.8-2.8 \%$ and from $3.1-6.0 \%$. The conditional damage type probabilities provide the average spread across the five considered categories. Hull and machinery and third party liabilities dominate for all ship types with conditional damage probabilities ranging from 33.6-52.1\%, whereas these probabilities are mostly well below $10 \%$ for pollution, loss of life, and cargo damages. Here it should be noted that cargo damage is not well represented in the incident data. The spread across the damage categories is similar for both types of seriousness (TLVSS and all) except for pollution and loss of life, which are consistently higher for TLVSS compared to all incident types. This finding reflects the IMO definitions of seriousness.

The risk components of Table A are integrated on the individual ship level into MVR by means of formula (1). Table 2 contains summary statistics of the resulting MVR. When based on all incidents, the average annual aggregate MVR-A is 76.9 billion USD (76.4 billion USD after excluding the fishing fleet and tugs), of which $33 \%$ is allocated to oil tankers and $30 \%$ to dry bulk carriers. When based on TLVSS incidents only, annual aggregate MVR-S is 38.8 billion USD ( 38.5 billion USD after excluding the fishing fleet and tugs), of which oil tankers represent $40 \%$ and dry bulk carriers $24 \%$. The highest average annual MVR per vessel applies, not surprisingly, for oil tankers, with a value of 1.8 million USD per tanker for MVRS (2.9 for MVR-A). In terms of MVR-S, second-highest are dry bulk carriers (0.9), followed by container vessels and passenger ships ( 0.7 each), general cargo vessels ( 0.2$)$, and other ship types (0.05).

Annual growth rates of MVR-S are highest for dry bulk carriers (28\%) followed by general cargo vessels $(19 \%)$, container vessels (13\%), other ship types (12\%), and passenger ships $(10 \%)$, but with hardly any growth for oil tankers $(0.1 \%)$. These growth rates are based on the period 2011-2014, because the database has incomplete fleet coverage for 2010. The main sources of growth apply for cargo (5-33\% per year), third party liabilities (11-28\%), and hull and machinery for dry bulk carriers (46\%), cargo vessels (17\%), and passenger ships (19\%). Passenger vessels show an annual increase of $7 \%$ in the MVR-S for loss of life. Further it is interesting to notice annual decreases in MVR-S of pollution for tankers $(-2 \%)$ and passenger vessels $(-11 \%)$, and of loss of life for tankers $(-2 \%)$ and dry bulk carriers $(-1 \%)$. The decrease in MVR-S of pollution for oil tankers confirms continuation of declining trends over earlier decades reported by Eliopoulou and Papanikolaou (2007) and ITOPF (2016). 
$<<$ Insert Table 2 around here. $>>$

\section{Spread of MVR across vessels and administrative dimensions}

To show the spread of MVR across individual vessels, Figure 1 presents MVR in disaggregated form using boxplots on the level of individual vessels. To improve readability, MVR is measured on a 10-log scale, so that one extra unit corresponds to multiplication of MVR by the factor 10. The boxplots show the range of risk exposure across the fleet by ship type and by damage type category. Observations above (below) the whiskers correspond to vessels with exceptionally high (low) MVR. The plots on the first row indicate such high MVR for some vessels for most ship types, those in the second row in particular for pollution and loss of life, and those in the bottom row for pollution of oil tankers. The bottom row shows that even within the single ship type of oil tankers there exists substantial variation in risk. It is therefore important to account for vessel specific safety qualities as source of uncertainty in vessel risk assessments (Vander Hoorn and Knapp, 2015).

Vessels can be classified along administrative dimensions by their flag state, classification society, DoC company, beneficial owner, and ship yard. The database contains 201 flags, 88 classification societies, 166 company locations, 195 owner locations, and 137 ship yard countries. Figure 2 provides a graphical representation of the variation in average annual MVR across the fleet by means of boxplots per flag, class, company, and owner. Total MVR for all ship types combined is shown at the top row and for oil tankers at the middle row, and the bottom row shows pollution MVR of all ship types. The boxplots show several outlying observations corresponding to exceptionally large MVR. For all vessel types combined, the top ten flags with highest risk exposure are Bermuda, Kenya, Netherlands Antilles, Isle of Man, the Bahamas, Liberia, Marshall Islands, Curacao, Greece, and Malta, with average exposure of 1.1-3.1 million USD per vessel per year. The top ten DoC company locations are Angola, Bermuda, Australia, Jordan, Libya, Greece, Canada, Israel, the Isle of Man, and Morocco, with average risk exposure of 1.1-4.2 million USD per vessel per year. The top ten ownership locations are Liberia, Jordan, Kenya, Isle of Man, Jersey, Bermuda, Marshall Islands, Monaco,

British Virgin Islands, and St. Kitts and Nevis, with average risk exposure of 1.5-5.4 million USD per vessel per year. The largest pollution MVR corresponding to the top outliers in the boxplots at the bottom row of Figure 2 correspond to flag 'flag not required', class 'Phoenix Register', DoC company location Angola, and owner location Hungary. These vessel groups consist mainly of oil tankers, and if vessels are restricted to oil tankers only then the top risk of pollution is for flag Vanuatu, class 'Union Bureau of Shipping', DoC location Romania, and owner location British Virgin Islands.

\section{$<<$ Insert Figures 1 and 2 around here. $>>$}

Table 3 complements Figures 1 and 2 with summary statistics per administrative dimension based on classifications of Alderton and Winchester (2002). Flags from old open registries show highest average risk exposure for all damage type categories, followed by 
international open registries and traditional maritime nations. For DoC companies, the highest risk exposure is found for companies located in high income countries, and the same applies for beneficial ownership except for hull and machinery and loss of life where owners from low income countries provide the highest risk. Table 3 also shows the top ten for classification societies and ship yard countries in terms of risk exposure for hull and machinery, which is the most relevant damage type category for these two dimensions.

As MVR measures risk exposure as proxy to potential damages, the above discussed risk information can be useful, for example, for port state authorities to develop ship inspection strategies and for insurance companies to evaluate the risk for individual flags, classes, companies, owners, and ship yards.

$<<$ Insert Table 3 around here. $>>$

\section{Annual risk exposure and insurance premiums}

We finally provide a connection between our assessments of maritime risk exposure with premium data of the maritime insurance industry. IUMI provided annual aggregate premium data for the period 2010-2014, split up over the insurance categories hull and machinery, cargo and transport, marine liabilities, and offshore and energy activities. The latter category falls outside the scope of our analysis, and we will also exclude cargo because insurance covers the whole logistic chain of which maritime transport is often only a limited part. Table 4 provides a high level comparison of global insurance premiums with MVR-A*, that is, MVR based on all incident types and adjusted by incorporating loss fractions per class of seriousness and per damage type, as was discussed above in our methodology. As IUMI and the P\&I clubs insure approximately 95 percent of all risk for hull and machinery and marine liabilities (Siddiqui and Verma, 2015), the IUMI premium figures for these two insurance categories have been scaled up by $5 \%$. When cargo is excluded, annual MVR-A* amounts to 15.1 billion USD, which comes reasonably close to annual premiums of 14.2 billion USD obtained from the marine insurers.

\section{$<<$ Insert Table 4 around here. $>>$}

Several factors complicate the comparison of premiums with actual risk exposure. Insurance is a global enterprise and involves many parties, and public insurance figures provide only a partial view of total risk exposure. A portion of total risk exposure is not insured due to vessel retentions or deductibles of about 200,000 per vessel (Cefor, 2015) that are not reported and that can vary depending on the insurance type and owner. Differences between premiums and claims are also needed to make insurance a viable enterprise, and ultimate claim to premium ratios for cargo and hull and machinery are about seventy percent (Seltmann, 2015). Furthermore, despite the high insurance limits of international conventions to cover large-scale incidents with catastrophic consequences (IMO, 2013), it is common that not all costs can be recovered (Grey, 1999; Kontovas et al, 2010). In addition, as stated before, cargo insurance 
contains the whole logistic chain and involves multiple parties, so that the reported IUMI premiums are much higher than risks related to the maritime portion only as measured by MVR. A breakdown of cargo insurance premiums along the various transport stages in the logistic chain is not available. In terms of insurance categories, it is therefore not surprising that the IUMI cargo transport insurance figures are much higher than the estimated monetary value at risk with respect the maritime portion of the cargo. Hull and machinery and third party liabilities are much better defined, resulting in much closer matches between risk exposure and premiums for these categories as reported in Table 4.

\section{Conclusion}

This paper presents an empirical risk analysis based on a comprehensive database for about 130,000 vessels over the period 2010-2014 with rich information on incidents and insurable values for each individual vessel. The main components of risk exposure, expressed in terms of the monetary value at risk (MVR), consist of the individual safety qualities of vessels, the total insurable value of vessels, and proxies for damage probabilities and loss fractions if an incident occurs. Two levels of seriousness of incidents are distinguished, with associated values of MVR. MVR-S is based on the classes of very serious (including total loss) and serious incidents (TLVSS) and is relevant for operational and strategic planning aspects to mitigate risk exposure by means of risk control options (such as alerting for high risk vessels or situations, improved targeting of vessels for inspections, and providing risk prediction scenarios for planning and allocation of assets across large areas). MVR-S can be interpreted as the potential damage amount for given vessel profile and insurable value, which can be combined with other layers such as metocean conditions and vessel traffic densities (Vander Hoorn and Knapp, 2015). MVR-A* is based on all incidents, TLVSS as well as less serious

ones, and incorporates adjustments of values at risk by means of estimated loss fractions needed to compare risk exposure with insurance premiums.

The total insurable value (TIV) based on requirements of the legislative framework and industry values is estimated to be 30.6 trillion USD per year for all ship types (including large fishing vessels and tugs), $49 \%$ of which is for oil tankers. In view of these large values, it is reassuring that oil tankers are identified as having the best safety quality of all vessel types, which is partly influenced by the numerous industry inspections carried out on tankers (Knapp, 2006). TIV is downscaled to MVR by incorporating individual ship risk profiles and estimated spreads across five damage type categories. The resulting annual global MVR is 76.9 billion USD when based on all incidents and 38.8 billion USD when based on TLVSS incidents only. The largest annual MVR-S values per damage type and per vessel are found for pollution of oil tankers (1.3 million USD), followed by loss of life for passenger vessels ( 0.5 million USD). Annual growth rates of MVR-S are large for some ship types, especially for dry bulk carriers (28\%), cargo vessels (19\%), and container vessels (13\%). As pollution and loss of life are major risk categories, it is important to note that the MVR-S has declined for pollution of tankers ($2 \%$ per year) whereas it has increased for loss of life of passenger vessels ( $7 \%$ per year).

The results confirm that MVR is unique to each vessel and varies across the fleet per damage type and per ship type. It is therefore important to account for vessel specific safety 
qualities as source of uncertainty in vessel risk assessments (Vander Hoorn and Knapp, 2015). A comparison across administrative dimensions reveals that most risk exposure still lies with old open registries and with beneficial owners and $\mathrm{DoC}$ companies located in high income countries. For beneficial owners, the risk exposure for hull and machinery and for loss of life is highest for owners from low income countries.

After applying loss fractions for the part of values that are lost at incidents, annual MVR-A* (excluding cargo) is estimated as 15.1 billion USD, compared to average annual IUMI premium figures of 14.3 billion USD. Part of the gap between risk exposure and premiums arises because some risks are not insured and deductibles of ship owners are not reported in the premium figures.

Our analysis shows that the proposed empirical framework for assessing maritime risk exposure in terms of MVR provides a basis for comparison with the risk coverage offered by the maritime insurance market. There exist several options for further improvement of this comparison. It would help if more detailed insurance data were available per damage category, in particular for pollution and loss of life that are currently subsumed under marine liabilities. Further, the calibration of loss fractions can be improved. As actual loss fractions for monetary losses are not publicly available, these fractions could be estimated here from empirical figures only for loss of life. In the ideal case that fully disaggregated premium data were available per vessel and per damage type, actuarial policies for premium determination could be analyzed from an empirical perspective by comparison with the monetary values at risk available in our database. Such an integration of premium data with empirical vessel-specific risk data could provide guidelines for better matching of premiums on the level of individual ships, underwriters, and owners.

\section{Acknowledgements}

We thank the data providers - IHS Markit, LLIS, IMO, AMSA and IUMI - for provision of their data, and we thank Astrid Seltmann from IUMI for explaining us some aspects of insurance markets.

\section{References}

Alderton, T., Winchester, N., 2002. Flag states and safety: 1997-1999. Maritime Policy and Management 29, 151-162

Bijwaard, G., Knapp, S., 2009. Analysis of ship life cycles - The impact of economic cycles and ship inspections. Marine Policy 33, 350-369.

Cefor, 2015. The 2015 Cefor Nomis Ocean Hull Report. http://www.cefor.no/Statistics/NOMIS/2015/. Accessed May 20, 2016.

Eliopoulou, E., Papanikolaou, A., 2007. Casualty analysis of large tankers. Journal of Marine Science and Technology 12, 240-250.

Greene, H.W., 2008. Econometric Analysis, sixth ed. Prentice Hall, New Jersey. 
Grey, C.J., 1999. The cost of oil spills from tankers: An analysis of IOPC fund incidents. Proceeding of the International Oil Spill Conference, 1999, http://www.itopf.com/costs.html

Hassel, M., Asbjørnslett, B., Hole, L.P., 2011. Underreporting of maritime accidents to vessel accident databases. Accident Analysis and Prevention 43, 2053-2063.

Heij, C., Knapp, S., 2012. Evaluation of safety and environmental risk at individual ship and company level. Transportation Research Part D 17, 228-236

International Maritime Organization, 2000. Reports on Marine Casualties and Incidents, Revised Harmonized Reporting procedures. MSC/Circ. 953, MEPC/Circ. 372, Adopted December 14, London.

International Maritime Organization, 2013. Convention on Limitation of Liability for Maritime Claims. http://www.imo.org/en/About/Conventions/ListOfConventions/Pages/ Convention-on-Limitation-of-Liability-for-Maritime-Claims-(LLMC).aspx

ITOPF (2016). http://www.itopf.com/knowledge-resources/data-statistics/statistics/

Knapp, S., 2006. The Econometrics of Maritime Safety - Recommendations to Enhance Safety at Sea. Doctoral thesis, Erasmus University, ERIM, http://hdl.handle.net/1765/7913

Knapp, S., 2013. An integrated risk estimation methodology: Ship specific incident type risk. Econometric Institute Report EI2013-11, http://repub.eur.nl/res/pub/39596/

Knapp, S., Bijwaard, G., Heij, C., 2011. Estimated incident cost savings in shipping due to inspections. Accident Analysis and Prevention 43, 1532-1539.

Kontovas, C.A., Psaraftis, H.N., Ventikos, N.P., 2010. An empirical analysis of IOPCF oil spill cost data. Marine Pollution Bulletin 60, 1455-1466

Li, K.X., Cullinane, K., 2003. An economic approach to maritime risk management and safety regulation. Maritime Economics and Logistics 5, 268-284.

Li, K.X., Wang, Y., Min, J. 2009. Quantitative analysis of materiality in marine insurance. Maritime Policy \& Management 36, 437-455.

Liu, X., Wirtz, K.W., 2006. Total oil spill costs and compensations. Maritime Policy and Management 33, 49-60.

Seltmann, A., 2015. Global Marine Insurance Report. http://www.cefor.no/Statistics/IUMUStatistics/2015/. Accessed May 20, 2016.

Siddiqui, A.W., Verma, M., 2013. An expected consequence approach to route choice in the maritime transportation of crude oil. Risk Analysis 33, 2041-2055.

Siddiqui, A.W., Verma, M., 2015. A bi-objective approach to routing and scheduling maritime transportation of crude oil. Transportation Research Part D 37, 65-78.

Stopford, M., 2009. Maritime Economics, third ed. Routledge, London.

Talley, W.K., 1999. Determinants of the property damage costs of tanker accidents. Transportation Research Part D 4, 413-426.

Vander Hoorn, S., Knapp, S., 2015. A multi-layered risk exposure assessment approach for the shipping industry. Transportation Research Part A: Policy and Practice 78, 21-33.

Willis Marine (2016). http://www.willis.com/pandipublications/index.html

Wood, J., 1995. Opa 90. Maritime Policy and Management 22, 201-208. 


\section{Appendix: Incident probabilities and total insurable values}

Table A: Incidents, incident probabilities, and total insurable values

\begin{tabular}{|c|c|c|c|c|c|c|}
\hline Ship type & Gen. cargo & Dry bulk & Container & Oil tanker & Passenger & Other \\
\hline \multicolumn{7}{|l|}{ Number of vessels and incidents } \\
\hline Vessels & 20,118 & 10,160 & 5,071 & 8,879 & 6,666 & 13,852 \\
\hline All types of incidents & 4,714 & 3,063 & 1,513 & 850 & 2,828 & 3,648 \\
\hline Hull and machinery & 3,215 & 3,779 & 1,167 & 570 & 1,549 & 1,845 \\
\hline Cargo & 139 & 121 & 90 & 10 & 45 & 106 \\
\hline Pollution & 148 & 129 & 66 & 68 & 55 & 314 \\
\hline Life & 76 & 38 & 17 & 17 & 31 & 174 \\
\hline Third party & 1,791 & 1,329 & 789 & 435 & 1,314 & 1,723 \\
\hline TLVSS incidents & 2,428 & 1,340 & 730 & 451 & 1,094 & 2,262 \\
\hline Hull and machinery & 1,113 & 489 & 262 & 162 & 479 & 770 \\
\hline Cargo & 18 & 15 & 16 & 2 & 13 & 23 \\
\hline Pollution & 88 & 101 & 48 & 43 & 37 & 266 \\
\hline Life & 71 & 33 & 17 & 17 & 27 & 172 \\
\hline Third party & 786 & 501 & 361 & 207 & 426 & 852 \\
\hline Less serious incidents & 2,286 & 1,723 & 783 & 399 & 1,734 & 1,386 \\
\hline \multicolumn{7}{|l|}{ Incident probabilities (\%) } \\
\hline All types of incidents & 4.3 & 5.4 & 5.6 & 2.3 & 6.0 & 3.1 \\
\hline Conditional hull and machinery & 45.3 & 42.2 & 38.5 & 39.8 & 52.1 & 33.1 \\
\hline Conditional cargo & 2.2 & 2.6 & 4.3 & 0.7 & 0.9 & 2.6 \\
\hline Conditional pollution & 4.1 & 4.9 & 4.7 & 7.5 & 1.7 & 8.3 \\
\hline Conditional life & 2.3 & 1.6 & 2.2 & 3.1 & 1.5 & 3.7 \\
\hline Conditional other third party & 36.1 & 39.2 & 46.8 & 42.9 & 33.6 & 45.7 \\
\hline TLVSS incidents & 2.4 & 2.6 & 2.8 & 1.4 & 2.6 & 1.8 \\
\hline Conditional hull and machinery & 41.5 & 32.7 & 31.7 & 38.5 & 45.0 & 31.1 \\
\hline Conditional cargo & 0.8 & 1.3 & 1.6 & 0.4 & 0.6 & 0.6 \\
\hline Conditional pollution & 5.0 & 9.5 & 7.3 & 8.5 & 2.2 & 14.6 \\
\hline Conditional life & 3.3 & 2.7 & 3.7 & 4.3 & 2.5 & 4.9 \\
\hline Conditional other third party & 36.7 & 39.7 & 48.1 & 44.2 & 37.7 & 42.4 \\
\hline \multicolumn{7}{|l|}{ Total insurable values } \\
\hline Average total per vessel (M USD) & 77 & 633 & 496 & 1,674 & 469 & 21 \\
\hline Hull and machinery & 6 & 42 & 24 & 49 & 3 & 2 \\
\hline Cargo & 55 & 513 & 395 & 393 & -- & 11 \\
\hline Pollution & 4 & 20 & 19 & 1,188 & 4 & 2 \\
\hline Life & 8 & 39 & 39 & 29 & 459 & 4 \\
\hline Other third party & 4 & 20 & 19 & 15 & 4 & 2 \\
\hline Aggregate over all vessels (B USD) & 1,545 & 6,432 & 2,518 & 14,860 & 3,129 & 290 \\
\hline$\%$ of total (30.6 trillion USD) & 5.0 & 21.0 & 8.2 & 48.6 & 10.2 & 0.9 \\
\hline
\end{tabular}

Table notes

The number of vessels is the annual average over 2010-2014, and the number of incidents is the sum total over these fives years; the incident probabilities and total insurable values are annual averages over 2010-2014; incidents of all types include all degrees of seriousnesses excluding near misses. 
Table 1: Data sources for TIV per damage type and comparison with IUMI categories

\begin{tabular}{|c|c|c|c|c|c|}
\hline \multirow[b]{2}{*}{ Damage category } & \multicolumn{3}{|c|}{ Total insurable value } & \multicolumn{2}{|c|}{ IUMI and P\&I CLubs } \\
\hline & Source / convention & Units & GRT (\%) & Category as compared to ours & Comparison \\
\hline Hull and machinery & SIN, vessel value & Second hand prices (USD/DWT) & -- & Same & Yes \\
\hline Cargo & UNCTAD, Global Insight & USD/DWT/day & -- & Larger, also non-maritime portion & Indirectly \\
\hline \multirow[t]{3}{*}{ Pollution } & $\mathrm{CLC}$ & SDR/GRT & 97 & Subsumed under marine liability & Via marine liability \\
\hline & IOPC & SDR (by Fund limits) & 94 & & \\
\hline & LLMC & SDR/GRT & 92 & & \\
\hline \multirow[t]{2}{*}{ Life } & Athens & SDR/passenger & 43 & Subsumed under marine liability & Via marine liability \\
\hline & LLMC & SDR/passenger/incident & 57 & & \\
\hline Other third party & LLMC & SDR/GRT & 57 & Subsumed under marine liability & Via marine liability \\
\hline Marine liability & -- & - & -- & Sum of pollution, life, third party & Yes \\
\hline Offshore & -- & -- & -- & Not available to us & No \\
\hline
\end{tabular}

Table notes

The left part of the table shows sources for our Total Insurable Values (TIV) per damage type, where GRT (\%) is the fleet coverage of conventions; the right part of the table compares the split-up of insurance premiums available from IUMI and P\&I Clubs with our damage categories. 
Table 2: Annual monetary value at risk and annual growth rates

\begin{tabular}{|c|c|c|c|c|c|c|}
\hline Ship type & Gen. cargo & Dry bulk & Container & Oil tanker & Passenger & Other \\
\hline \multicolumn{7}{|l|}{ Aggregate MVR of all vessels ( $B$ USD) } \\
\hline For all types of incident (MVR-A) & 7.2 & 23.3 & 8.9 & 25.6 & 7.0 & 1.4 \\
\hline Percentage of total (76.9) & 9.4 & 30.3 & 11.6 & 33.3 & 9.0 & 1.8 \\
\hline For TLVSS incidents only (MVR-S) & 3.3 & 9.2 & 3.5 & 15.5 & 4.6 & 0.7 \\
\hline Percentage of total (38.8) & 8.6 & 23.8 & 9.1 & 40.1 & 12.0 & 1.8 \\
\hline Percentage MVR-S of MVR-A & 46.5 & 39.7 & 39.7 & 60.7 & 66.8 & 51.6 \\
\hline \multicolumn{7}{|l|}{ Average MVR-A per vessel (M USD) } \\
\hline Total & 0.36 & 2.30 & 1.76 & 2.88 & 1.04 & 0.10 \\
\hline Hull and machinery & 0.17 & 1.12 & 0.47 & 0.56 & 0.18 & 0.03 \\
\hline Cargo & 0.07 & 0.60 & 0.68 & 0.12 & -- & 0.02 \\
\hline Pollution & 0.01 & 0.05 & 0.04 & 1.92 & 0.01 & 0.01 \\
\hline Life & 0.01 & 0.03 & 0.04 & 0.03 & 0.59 & 0.01 \\
\hline Other third party & 0.10 & 0.49 & 0.53 & 0.25 & 0.26 & 0.04 \\
\hline \multicolumn{7}{|l|}{ Average MVR-S per vessel (M USD) } \\
\hline Total & 0.17 & 0.91 & 0.70 & 1.75 & 0.70 & 0.05 \\
\hline Hull and machinery & 0.08 & 0.41 & 0.19 & 0.27 & 0.06 & 0.01 \\
\hline Cargo & 0.02 & 0.21 & 0.18 & 0.05 & -- & 0.00 \\
\hline Pollution & 0.01 & 0.05 & 0.03 & 1.27 & 0.01 & 0.01 \\
\hline Life & 0.01 & 0.04 & 0.04 & 0.03 & 0.54 & 0.01 \\
\hline Other third party & 0.05 & 0.22 & 0.25 & 0.13 & 0.09 & 0.02 \\
\hline \multicolumn{7}{|l|}{ Percentage growth rate of MVR-S } \\
\hline Total & 18.7 & 27.8 & 12.6 & 0.1 & 10.1 & 12.0 \\
\hline Hull and machinery & 16.6 & 45.7 & 2.1 & 4.1 & 18.7 & 8.1 \\
\hline Cargo & 32.6 & 20.9 & 22.0 & 5.1 & -- & 22.0 \\
\hline Pollution & 0.5 & 3.5 & 1.2 & -2.0 & -11.3 & 12.0 \\
\hline Life & 5.9 & -1.4 & 15.0 & -1.9 & 6.9 & 8.7 \\
\hline Other third party & 21.9 & 17.5 & 18.3 & 10.5 & 27.6 & 13.7 \\
\hline
\end{tabular}

Table notes

Aggregate MVR is the average over 2010-2014 of the annual sum total of the monetary value at risk of all vessels (expressed in billion USD), based on all incidents (MVR-A) or TLVSS incidents only (MVR-S); average MVR is the corresponding average annual monetary value at risk per vessel (expressed in million USD; no values apply for cargo of passenger ships); percentage growth rates apply for the period 2011-2014, computed as $(100 / 3)^{*}(x 14-x 11) / x 11$ with $x 11$ and $x 14$ the MVR-S in respectively 2011 and 2014. 
Figure 1: Box plots of average annual monetary value at risk per vessel (on logarithmic scale)
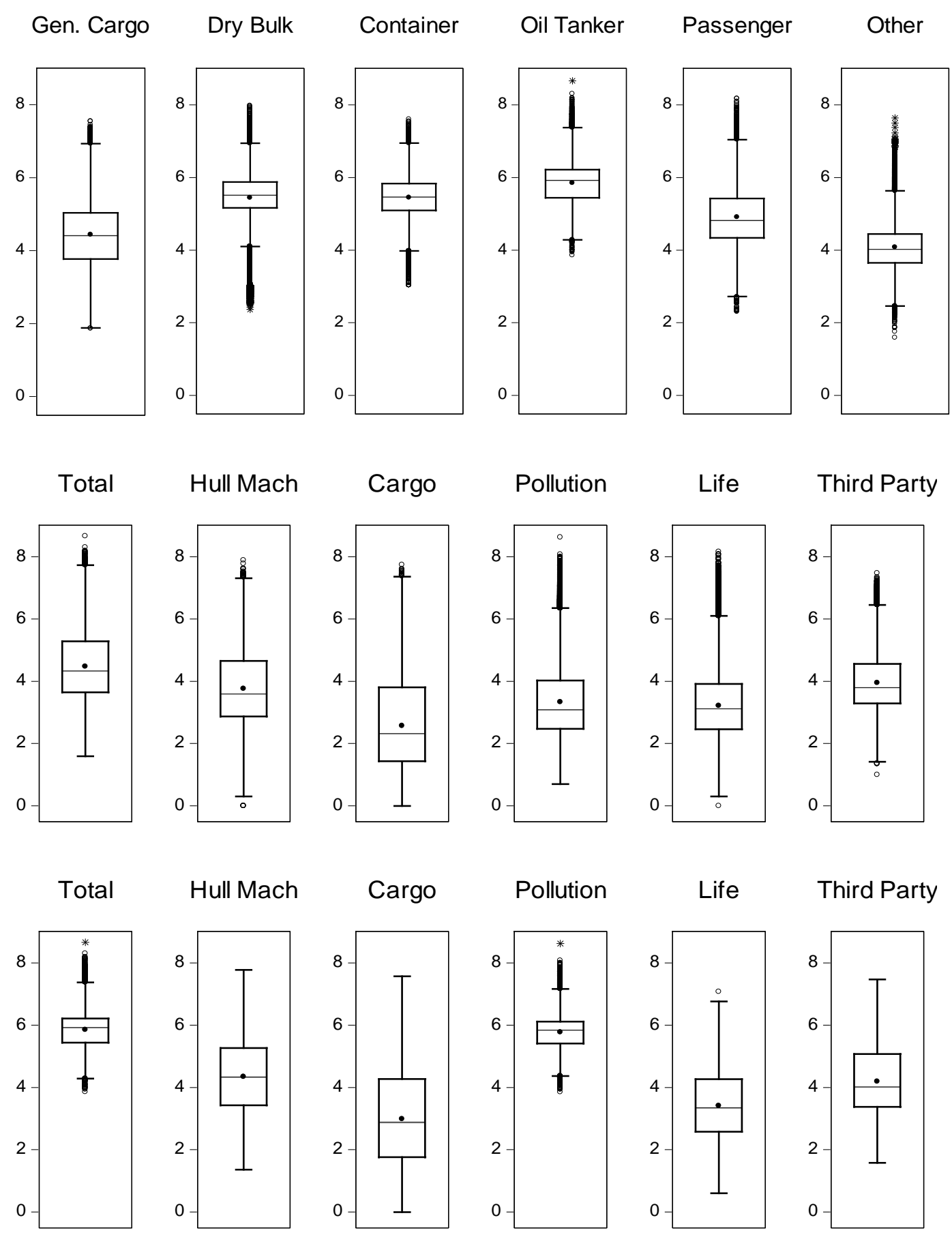

Figure caption

Box plots for the average annual monetary value at risk due to TLVSS incidents (MVR-S) per vessel for six ship types (top row), for five damage types (middle row), and for five damage types for oil tankers (bottom row); values are base-10 logarithms of the annual average over 2010-2014 so that, for example, a value of 6 means one million USD on average per year. 
Figure 2: Average annual monetary value at risk (in million USD per vessel)

Flag

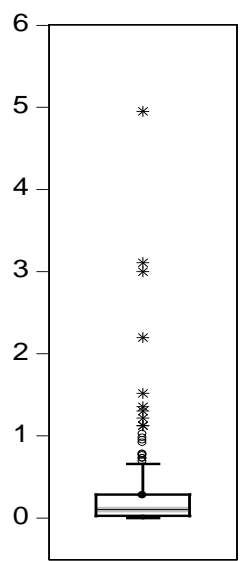

Flag

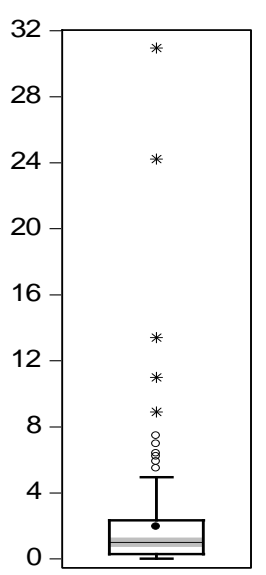

Flag

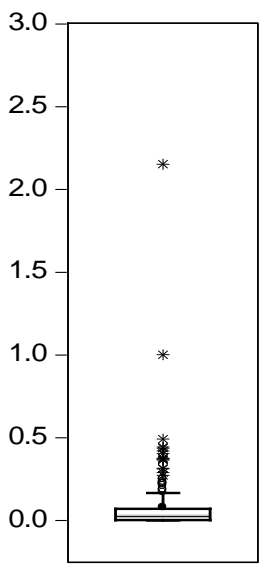

Class

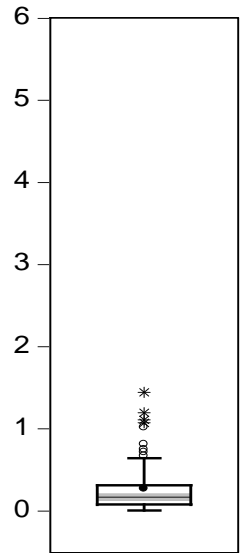

Class

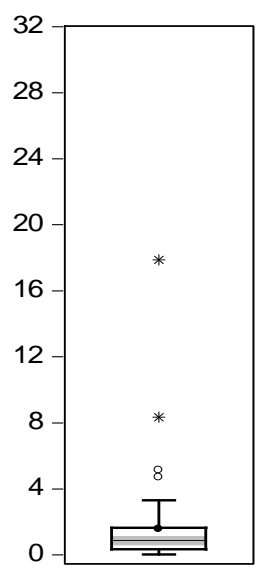

Class



DoC

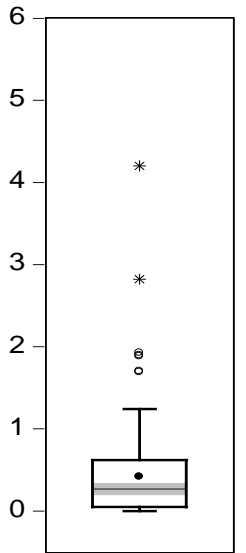

DoC

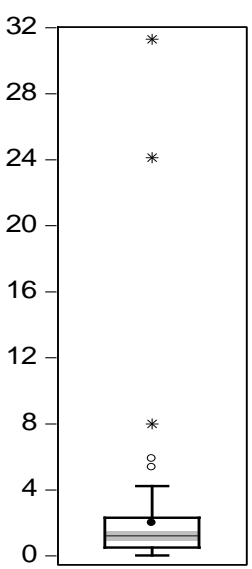

DoC

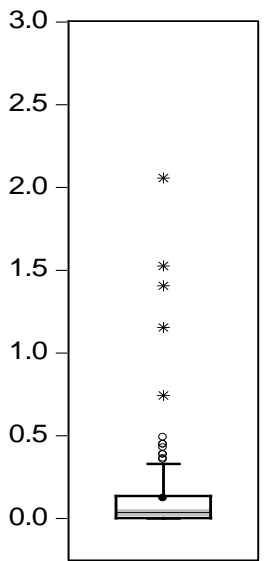

Owner

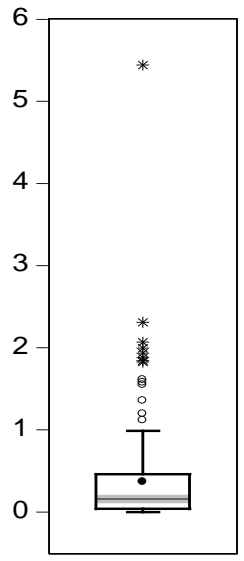

Owner



Owner

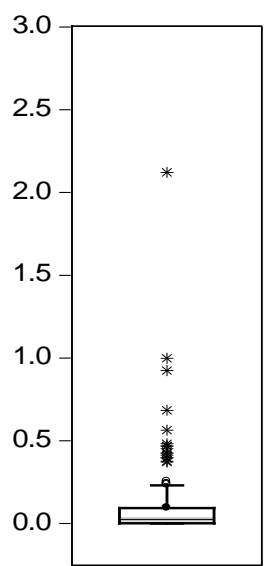

Figure caption

Box plots for the average annual monetary value at risk due to TLVSS incidents (MVR-S, in million USD per vessel), for all ship types (top row), for oil tankers (middle row), and for pollution of all ship types (bottom row), for 201 flags, 88 classification societies, 166 DoC company countries of location, and 195 owner countries of location; scales are fixed per row. 
Table 3: Annual average monetary value at risk along administrative dimensions (in thousand USD)

\begin{tabular}{|c|c|c|c|c|c|c|}
\hline & Hull Mach & Cargo & Pollution & Life & Third party & Total \\
\hline \multicolumn{7}{|l|}{ Flag of registration group } \\
\hline Old open registries & 277 & 125 & 219 & 89 & 184 & 895 \\
\hline International open registries & 146 & 62 & 206 & 38 & 98 & 551 \\
\hline Traditional maritime nations & 58 & 17 & 122 & 47 & 47 & 290 \\
\hline New open registries & 95 & 26 & 79 & 28 & 48 & 276 \\
\hline Unknown registries & 63 & 37 & 57 & 11 & 37 & 205 \\
\hline Emerging maritime nations & 36 & 3 & 59 & 34 & 26 & 157 \\
\hline \multicolumn{7}{|l|}{ Beneficial owner country of location } \\
\hline High income & 167 & 69 & 166 & 71 & 116 & 589 \\
\hline Upper middle income & 134 & 50 & 144 & 44 & 85 & 458 \\
\hline Lower middle income & 56 & 8 & 79 & 68 & 33 & 343 \\
\hline Low income countries & 174 & 14 & 51 & 85 & 18 & 245 \\
\hline Unknown owner location & 17 & 5 & 65 & 10 & 15 & 111 \\
\hline \multicolumn{7}{|l|}{ DoC company country of location } \\
\hline High income & 203 & 86 & 189 & 75 & 137 & 690 \\
\hline Upper middle income & 164 & 51 & 119 & 37 & 119 & 491 \\
\hline Lower middle income & 116 & 21 & 80 & 66 & 77 & 361 \\
\hline Unknown company location & 31 & 10 & 81 & 29 & 22 & 172 \\
\hline Low income countries & 19 & 4 & 57 & 11 & 36 & 126 \\
\hline Top-10 classes and ship yards & Hull Mach & & & & Hull Mach & \\
\hline Classification society & & & Ship yard cou & & & \\
\hline Registrul Naval Roman & 658 & & Korea, South & & 318 & \\
\hline DNV-GL & 493 & & Croatia & & 306 & \\
\hline Lloyd's Register & 273 & & Brazil & & 258 & \\
\hline Korean Register of Shipping & 258 & & Belgium & & 245 & \\
\hline Registro Italiano Navale & 233 & & Philippines & & 218 & \\
\hline Nippon Kaiji Kyokai & 204 & & Bulgaria & & 196 & \\
\hline Panama Maritime Documentation & 194 & & Portugal & & 166 & \\
\hline Phoenix Register of Shipping & 182 & & China & & 164 & \\
\hline American Bureau of Shipping & 181 & & Russia & & 163 & \\
\hline China Classification Society & 163 & & Argentina & & 136 & \\
\hline
\end{tabular}

Table notes

The table shows the average annual monetary value at risk per vessel based on TLVSS incidents only (MVR-S, expressed in thousand USD), ranked from high to low according to total value for flag, owner, and DoC, and according to hull and machinery for classification societies and ship yard countries. 
Table 4: Global annual insurance premiums and monetary risk exposure (for estimated loss fraction scenario)

\begin{tabular}{|c|c|c|c|c|c|c|c|c|}
\hline & Hull Mach & Cargo & Pollution & \multicolumn{3}{|c|}{ Life Third party Marine liab } & Total & Ex cargo \\
\hline Total loss and very serious ( $\# 1,731$ ) & 95 & 95 & 5 & 4 & 95 & -- & -- & -- \\
\hline Serious (\# 7,818) & 60 & 60 & 1 & 1 & 60 & -- & -- & -- \\
\hline Less serious (\# 9,053) & 5 & 5 & 0 & 0 & 5 & -- & -- & -- \\
\hline Weighted loss fractions & 36.5 & 36.5 & 0.9 & 0.8 & 36.5 & -- & -- & -- \\
\hline \multicolumn{9}{|l|}{ MVR and premiums (M USD) } \\
\hline Aggregate MVR-A (all incidents) & 25,313 & 12,677 & 18,295 & 5,120 & 15,456 & 38,871 & 76,861 & 64,184 \\
\hline MVR-A corrected by loss fractions & 9,237 & 4,626 & 162 & 41 & 5,640 & 5,843 & 19,705 & 15,079 \\
\hline Premiums IUMI and P\&I Clubs & 8,463 & 17,233 & -- & -- & -- & 5,799 & 31,496 & 14,263 \\
\hline Premiums over risk exposure & 0.92 & 3.73 & -- & -- & -- & 0.99 & 1.60 & 0.95 \\
\hline
\end{tabular}

\section{Table notes}

Weighted loss fractions are weighted averages of loss fractions per class of seriousness, with weights equal to the share of each class (9.3\% TLVS, $42.0 \%$ serious, and $48.7 \%$ less serious); aggregate MVR-A is the average annual total monetary value at risk for all incident types summed over all vessels (including general cargo, dry bulk, container, tanker, passenger, and other ship types as well as fishing ships and tug boats, with 130,307 vessels in total over 2010-2014); marine liability is the sum total of pollution, life, and other third party liabilities; the column "Total" shows the sum total of hull and machinery, cargo, and marine liability, and the column "Ex cargo" is obtained from "Total" by omitting cargo. 